\title{
Dissolution Test for Mianserin Hydrochloride in Tablets
}

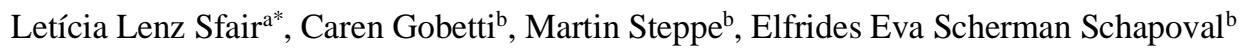 \\ ${ }^{a}$ Escola de Saúde, Curso de Farmácia, Universidade do Vale do Rio dos Sinos, Av. Unisinos 950, 93022-750, São \\ Leopoldo, Brasil; \\ ${ }^{b}$ Faculdade de Farmácia, Universidade Federal do Rio Grande do Sul, Av. Ipiranga 2752, CEP 90610-000, Porto Alegre, \\ Brasil.
}

\section{*Corresponding author: leticiasfair@hotmail.com}

\begin{abstract}
A dissolution test for mianserin hydrochloride in coated tablets containing $30 \mathrm{mg}$ was developed and validated using a fast ultraviolet spectrophotometric method. The appropriate conditions were determinate after testing sink conditions, agitation speed and dissolution medium. The sink conditions tested showed that mianserin hydrochloride was soluble in 0.01 and $0.1 \mathrm{M}$ hydrochloric acid $(\mathrm{HCl})$, acetate buffer $\mathrm{pH} 4.1$ and 5.0 and phosphate buffer $\mathrm{pH}$ 6.8. Then, dissolution tests were performed to investigate the drug release in each medium. Optimal conditions to carry out the dissolution test were $900 \mathrm{~mL} 0.1 \mathrm{M} \mathrm{HCl}$ and USP apparatus 2 (paddle) at $50 \mathrm{rpm}$ stirring speed. The quantification method was also adapted and validated. The UV method showed specificity, linearity, precision and accuracy. The in vitro dissolution test can be used to evaluate the drug release profile and the data was used as an aid to establish a possible correlation with in vivo data.
\end{abstract}

Keywords: Mianserin hydrochloride; Dissolution test; UV method; Quality control; IVIVC

\section{Introduction}

Mianserin hydrochloride (Fig. 1) is a drug for the treatment of depressive illness and depression associated with anxiety. It is classified as an atypical antidepressant, based on their mechanism of action is not defined. Acts by blocking presynaptic alpha- 2 receptors in the brain, resulting in higher levels of norepinephrine in the synaptic cleft and has antagonist activity at serotonin receptors $[1,2]$.

In the literature is not described the biopharmaceutics classification of mianserin hydrochloride, but we believe that the drug is a class III based on data of solubility and bioavailability. In the case of high solubility/low permeability drugs (class III), permeability is the rate controlling step and a limited IVIVC may be possible, depending on the relative rates of dissolution and intestinal transit. IVIVC is defined as the correlation between in vitro dissolution and in vivo input rate and may be used as an alternative to minimize unnecessary tests with humans [3]. The biopharmaceutics classification system (BCS) suggests that for high solubility, high permeability (class I) drugs and in some instances for high solubility, low permeability (class III) drugs, $85 \%$ dissolution in $0.1 \mathrm{M} \mathrm{HCl}$ in 15 minutes can ensure that the bioavailability of the drug is not limited by dissolution. In these cases, the rate limiting step for drug absorption is gastric emptying [3].

There is real need to develop dissolutions tests that can predict more effectively the in vivo behavior of dosage forms, should lead not only to reduce costs and work needed the development of a pharmaceutical form, but also the number and size of clinical studies required and more reliable quality control.

Dissolution testing should be carried out using basket at $50 / 100$ or paddle at $50 / 75$, at 15 min intervals to generate a profile. To evaluate the profile of drugs that dissolve quickly, sampling should occur at shorter intervals, from 5 to $10 \mathrm{~min}$ [3].

Drug absorption from a solid dosage form after oral administration depends on the release of the drug substance from the product, the dissolution or solubilization of the drug under physiological conditions and the permeability across the gastrointestinal tract. Then, in vitro dissolution may be relevant to the prediction of in vivo performance [3]. A more discriminating dissolution method is preferred because the test will indicate possible changes in the quality of the product before in vivo performance is affected [4].

Although the literature describe some analytical methods for quantification of mianserin hydrochloride in biological fluids $[2,5,6]$ and pharmaceutical formulation [7], there is no dissolution test for this pharmaceutical dosage form reported. The aim of the present study was to develop dissolution test and validate an analytical method in order to evaluate the release profile of this drug.

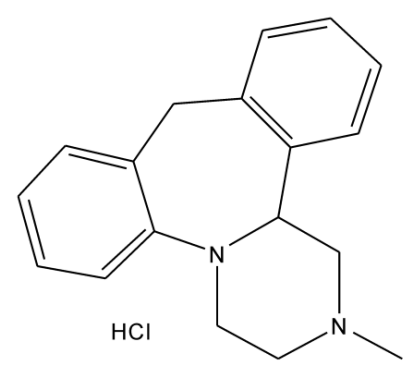

Figure 1. Chemical structure of mianserin hydrochloride.

\section{Material and methods}

\section{Instrumentation}

The dissolution tests were performed in a Vankel® VK 7010 multi-bath $(\mathrm{n}=8)$, auto-sampling consisting of a bidirectional peristaltic pump, VK 750D digitally controlled heater, in accordance with United States Pharmacopoeia (USP) general methods [8]. Spectral and absorbance measurements were performed with an UV-Vis Shimadzu model UV 160A using quartz cells and detection at $278 \mathrm{~nm}$. The Digimed potenciometer, model DM-20 (São Paulo, Brazil) was used to determine the $\mathrm{pH}$ of the solutions. The HPLC system (Agilent 1200 series, Santa Clara, USA) consisted of a G1311A 
quaternary pump, G1322A vacuum degasser, G1316A thermostat column compartment, G1329A standard auto sampler and G1315B diode array detector set at $278 \mathrm{~nm}$. Chromatographic analysis were performed in an Ace RP-18 octadecyl silane column $(250 \mathrm{~mm} \times 4.6 \mathrm{~mm}$ i.d., particle size 5 $\mu \mathrm{m})$ maintained at ambient temperature $\left(25^{\circ} \mathrm{C}\right)$. The mobile phase was composed of methanol, monobasic potassium phosphate buffer and triethylamine solution adjusted to $\mathrm{pH}$ 7.0 in isocratic mode at a flow rate of $1.0 \mathrm{~mL} / \mathrm{min}$ and the sample injection volume was $20 \mu \mathrm{L}$.

\section{Material and Reagents}

Mianserin hydrochloride reference standard (99.90\%) was kindly supplied by Pharmaceutical Industry Organon (Schering-Plough, São Paulo, Brazil) and the commercial tablets Tolvon ${ }^{\circledR}$ was obtained in the local market. The excipients of pharmaceutical formulation were starch, silicon dioxide, magnesium stearate, methylcellulose, calcium dibasic phosphate, hypromellose, macrogol and titanium dioxide. Water was purified using Millipore® system. All the other reagents were of analytical grade and buffer solutions were prepared according to USP 42 [8].

\section{Dissolution tests conditions}

The dissolution profiles should be performed in at least three different dissolution media, within the physiological $\mathrm{pH}$ range [3]. The selection of the dissolution medium is made by considering, in part, the solubility of the drug in order to ensure sink conditions [9]. The sink conditions were determined in different solvents: 0.01 and $0.1 \mathrm{M} \mathrm{HCl}$, acetate buffer $\mathrm{pH} 4.1$ and 5.0 and phosphate buffer $\mathrm{pH}$ 6.8. Water is not tested, since it is not an ideal dissolution medium. First, because the variability of the quality of the water from different sources, and second, the variability of the $\mathrm{pH}$ from day to day [3, 8]. For dissolution tests, $900 \mathrm{~mL}$ of each medium were deaerated, by stirring and heating, and maintained at $37 \pm 0.5^{\circ} \mathrm{C}$. USP apparatus, paddle and basket, were tested. For paddle was tested stirring speeds of 50 and $75 \mathrm{rpm}$ and for basket was tested 75 and $100 \mathrm{rpm}$. The test time was set on $90 \mathrm{~min}$.

\section{Validation}

In order to demonstrate whether the method was adequate for dissolution test purposes, it was validated through the analysis of specificity, linearity, precision and accuracy $[3,8,9]$.

\section{Stability}

Stability of mianserin hydrochloride in the dissolution medium selected was evaluated using standard and sample solutions. The solutions were kept at room temperature $\left(25^{\circ} \mathrm{C}\right)$ for $24 \mathrm{~h}$. Aliquots of the solutions were analyzed at time 0,1 and $24 \mathrm{~h}$. The obtained results were compared with a freshly solution.

\section{Specificity}

It is necessary to demonstrate that the results are not affected by placebo constituents [8]. Placebo sample of commercial product (Tolvon ${ }^{\circledR}$ ) was prepared in its usual compositions. The equivalent of an average weight of the mixture of excipients was transferred to separate vessels $(n=2)$ with $900 \mathrm{~mL}$ of the dissolution medium at $37 \pm 0.5^{\circ} \mathrm{C}$ and stirred for $1 \mathrm{~h}$ at $150 \mathrm{rpm}$ using paddle (USP apparatus 2). After 1 $\mathrm{h}$, aliquots of these solutions were filtered and analyzed by the UV method at $278 \mathrm{~nm}$. Placebo interference is available by the formula: $100 \mathrm{C}(\mathrm{AP} / \mathrm{AS})(\mathrm{V} / \mathrm{L})$, in which $\mathrm{C}$ is the concentration $(\mathrm{mg} / \mathrm{mL})$ of standard solution; AP and AS are the absorbances of placebo and standard; $\mathrm{V}$ is the volume of the medium and $\mathrm{L}$ is the label claim (mg). According to USP, the interference should not exceed $2.0 \%$.

\section{Linearity}

Linearity is established by preparing solutions, ranging in concentration from below the lowest expected concentration to above the highest concentration during release. Aliquots of a $100.0 \mu \mathrm{g} / \mathrm{mL}$ solution of mianserin hydrochloride reference standard, prepared in $0.1 \mathrm{M} \mathrm{HCl}$, were transferred to $20 \mathrm{~mL}$ volumetric flasks to obtain the final concentration of 5.0, $10.0,15.0,20.0,25.0,30.0$ and $40.0 \mu \mathrm{g} / \mathrm{mL}$. To evaluate the linearity of the analytical method, three standard curves were constructed in three different days. The linearity was evaluated by linear regression analysis, which was calculated by the least squares regression method and analysis of variance (ANOVA).

\section{Precision}

Repeatability and intermediate precision were used to assess the precision of the method. Repeatability was evaluated through relative standard deviation (RSD) from the recovery data at $100 \%$ level [4] at two different days and the intermediate precision through the RSD inter-day. The recovery data were performed, in triplicate, by adding an amount of powder equivalent to $30.0 \mathrm{mg}(100 \%$ of the nominal assay) of mianserin hydrochloride reference standard to a placebo sample. The dissolution test was done for $30 \mathrm{~min}$ using $900 \mathrm{~mL}$ of dissolution medium $0.1 \mathrm{M} \mathrm{HCl}$ at $37 \pm$ $0.5^{\circ} \mathrm{C}$, apparatus 2 (paddle) rotating at $50 \mathrm{rpm}$. Aliquots of $10.0 \mathrm{~mL}$ were filtered with $0.45 \mu \mathrm{m}$ nylon filter and analyzed by UV method at $278 \mathrm{~nm}$.

\section{Accuracy}

This parameter was determined by the recovery test, which consists in adding known amounts of mianserin hydrochloride reference standard to placebo solution at 10 , 100 and $150 \%(3.0,30.0$ and $45.0 \mathrm{mg})$ of the nominal assay of mianserin. These concentrations were determine based on other papers published in the literature. The dissolution test was done for $30 \mathrm{~min}$ using $900 \mathrm{~mL}$ of dissolution medium 0.1 $\mathrm{M} \mathrm{HCl}$ at $37 \pm 0.5^{\circ} \mathrm{C}$, USP apparatus 2 rotating at $50 \mathrm{rpm}$. Aliquots of $10.0 \mathrm{~mL}$ were filtered with $0.45 \mu \mathrm{m}$ nylon filter and analyzed by UV method at $278 \mathrm{~nm}$. Each concentration was prepared in duplicate. 


\section{Robustness}

It was evaluated by the influence of dissolution medium deaeration affects the liberation profile of mianserin hydrochloride from the tablets. Medium deaeration was used to eliminate air bubbles before the dissolution test.

\section{Dissolution profiles}

The dissolution profiles were obtained after the determination of the best dissolution conditions tests. Aliquots of $10.0 \mathrm{~mL}$ were withdrawn from each vessel without replacement of dissolution medium. Later, calculations were performed for volume correction. The times selected were: $5 ; 10 ; 15 ; 30 ; 45$; 60 and $90 \mathrm{~min}$. The samples were first filtered in a $10.0 \mu \mathrm{m}$ filter and then in $0.45 \mu \mathrm{m}$ nylon filter. The samples were analyzed by UV method at $278 \mathrm{~nm}$.

\section{In vitro-in vivo correlation}

The data was used as an aid to establish a possible correlation with in vivo data. The average plasma concentration versus time curve was fitted with a non-linear software (Micromath Scientist ${ }^{\circledR}$, v.2.01) using a one-compartment model. An IVIVC for mianserin hydrochloride was evaluated by plotting the mean percentage of drug absorbed (FA) versus the mean percentage of drug dissolved (FD).

\section{Results and discussion}

The sink conditions tested showed that mianserin hydrochloride was soluble in 0.01 and $0.1 \mathrm{M} \mathrm{HCl}$, acetate buffer $\mathrm{pH} 4.1$ and 5.0 and phosphate buffer $\mathrm{pH}$ 6.8. Then, dissolution tests were performed to investigate the drug release in each medium. Initially was used a validated stability-indicating HPLC method [10] to analyze the dissolution profile of the samples (Fig. 2).

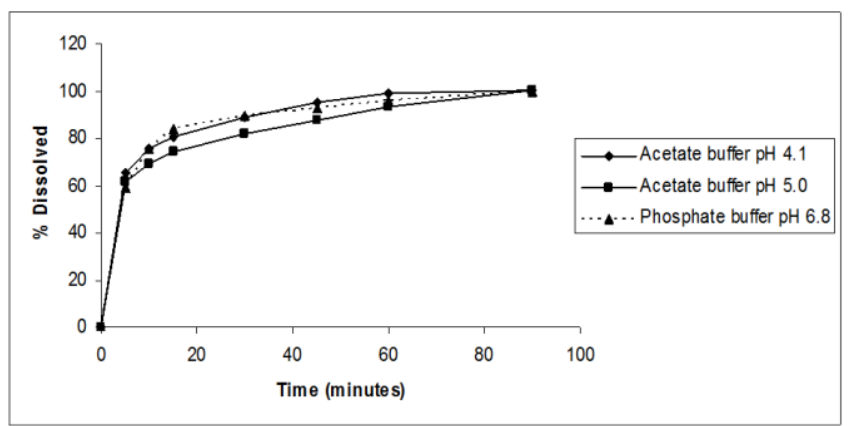

Figure 2. Dissolution profiles of mianserin hydrochloride tablets using acetate buffer $\mathrm{pH} 4.1$, acetate buffer $\mathrm{pH} 5.0$ and phosphate buffer $\mathrm{pH} 6.8$ and apparatus 2 rotating at $75 \mathrm{rpm}$.

However, optimal conditions to carry out the dissolution test were $900 \mathrm{~mL} 0.1 \mathrm{M} \mathrm{HCl}$ at $37 \pm 0.5^{\circ} \mathrm{C}$, USP apparatus 2 (paddle) at $50 \mathrm{rpm}$ stirring speed using UV method at $278 \mathrm{~nm}$ (Fig. 3). The UV method requires no expensive or complex equipment and needs no toxic solvents [11]. The preferred method of analysis is spectrophotometric determination because results can be obtained faster, the analysis is simpler and fewer solvents are used, making this valuable in routine analysis $[4,12]$. The choice of $0.1 \mathrm{M} \mathrm{HCl}$ as medium is due to its good solubility, accessibility, low cost and the fact that is a typical dissolution medium [9].
To evaluate mianserin hydrochloride stability, the standard and sample solutions dissolved in $0.1 \mathrm{M} \mathrm{HCl}$, were kept at room temperature for a period of $24 \mathrm{~h}$. According to the literature, the acceptable range for solution stability is 98$102 \%$ of the initial value [9]. The solutions remained stable for the time period specified.

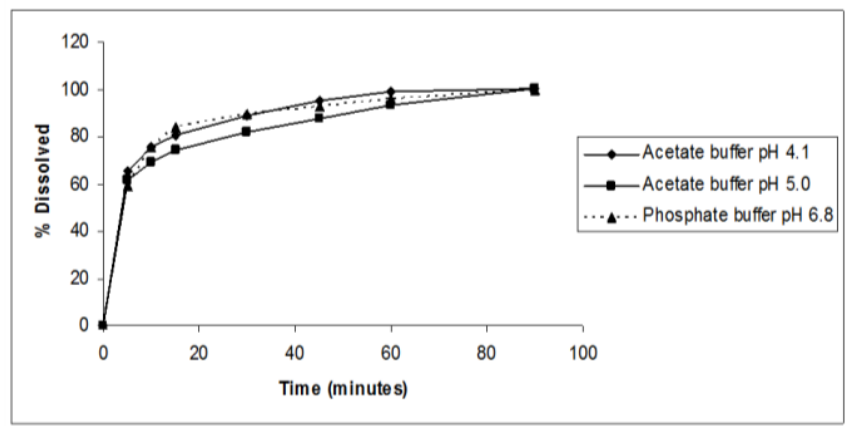

Figure 3. Tablets dissolution profile using $\mathrm{HCl} 0.1 \mathrm{M}$ and paddle at $50 \mathrm{rpm}$.

The specificity analysis of placebo solution revealed that the UV method suffered no interference from the formulation excipients when the solution is filtered by $\quad 0.45 \mu$ m nylon filter. However, when the placebo solution was only filtered by $10.0 \mu \mathrm{m}$ filter, the interference from pharmaceutical excipients is above the allowed (Fig. 4). According to the calculation of specificity recommended by USP, the interference of excipients was less than $2.0 \%$. Thus, the UV method is useful to quantify mianserin hydrochloride in pharmaceutical formulation from the dissolution tests.

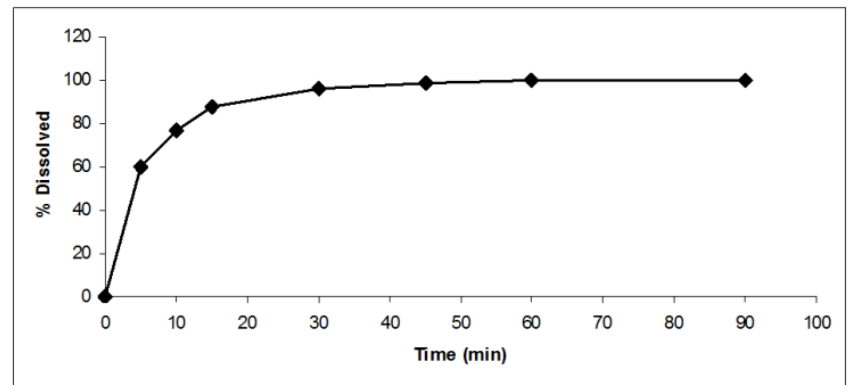

Figure 4. UV spectrum of mianserin hydrochloride reference standard ( $($ ) and placebo (...) before (A) and after (B) filtration with $0.45 \mu \mathrm{m}$ nylon filter to the dissolution test in $0.1 \mathrm{M} \mathrm{HCl}$ at $37 \pm$ $0.5^{\circ} \mathrm{C}$ and paddle rotating at $150 \mathrm{rpm}$ for $1 \mathrm{~h}$.

To assess the linearity, three standard curves for mianserin hydrochloride were constructed, plotting concentrations $(\mu \mathrm{g} / \mathrm{mL})$ versus absorbance and showed good linearity on the $5.0-40.0 \mu \mathrm{g} / \mathrm{mL}$ range. The representative linear equation was $y=0.0073 x+0.0111$ and the correlation coefficient was $r=0.9998$. The data were validated by means of the analysis of variance (ANOVA), which demonstrated significant linear regression and no significant linearity deviation $(\mathrm{p}<0.05)$ $($ Fcal $=1.15)$.

The precision of the dissolution tests was determined by repeatability (intra-day) and intermediate precision (interday) and it was expressed as RSD (\%). The low values of relative standard deviations for the repeatability $(1.32 \%$ and $1.05 \%)$ and intermediate precision (1.77\%) demonstrated adequate precision of the analytical method (Table 1). 
Table 1. Precision of the dissolution method for mianserin.

\begin{tabular}{ccc}
\hline \multirow{2}{*}{ Samples } & Assay (\%) & Day 2 \\
\cline { 2 - 3 } & Day 1 & 99.40 \\
1 & 102.73 & 101.80 \\
2 & 104.77 & 99.78 \\
\hline 3 & 101.47 & 100.33 \\
Mean & 102.99 & 1.05 \\
\hline RSD (\%) & 1.32 & \\
\hline
\end{tabular}

The accuracy was demonstrated by the recovery of known amounts of mianserin hydrochloride in the dissolution vessels. Percentage recoveries from $95.0 \%$ to $105.0 \%$ are recommended $[4,8]$. In the accuracy test, three concentrations were evaluated $(3.33,33.33$ and $50.0 \mu \mathrm{g} / \mathrm{mL}$ ) and mean recoveries were $99.08 \pm 1.95,102.17 \pm 1.88$ and $100.27 \pm$ $0.81 \%$, respectively.

In the evaluation of the robustness of the method [13], the presence of possible air bubbles in the dissolution medium no interference in the dissolution profile of the mianserin hydrochloride in tablets.

To establish a possible correlation with in vivo data, was used the pharmacokinetic data available from the literature [2]. In this paper referenced, the values of Cmax (peak plasma concentration) and tmax (time to reach Cmax) were calculated and the others parameters were calculated using one compartmental model by Drug and Statistics Software. Based on these results, the plasma concentration versus time profile curve was transformed into percentage of drug absorbed (FA) versus time, using Wagner-Nelson method (Fig. 5).
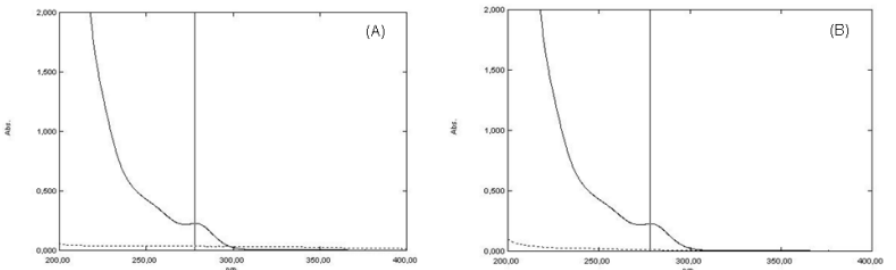

Figure 5. Percentage of drug absorbed (FA) versus time curve for mianserin hydrochloride tablets using Wagner-Nelson method.

The level-A correlation is the highest level of correlation that can be obtained. Represents a point to point relationship between in vitro dissolution data and in vivo absorption data of the drug from the dosage form [14].

The analysis of percentage of drug absorbed (FA) versus the percentage of drug dissolved (FD) cannot be evaluated by linear regression, because there was not obtained a straight (fig. 6). It was not possible to establish a level-A in vitro-in vivo correlation for mianserin hydrochloride and one factor that may have hindered the correlation was the rapid drug release in the initial points of dissolution test. For BCS class III drugs - high solubility, low permeability - there is a limited crossing of the GI wall. In vitro dissolution will not predict in vivo absorption. It was not expect a level A correlation, but a limited correlation was possible.

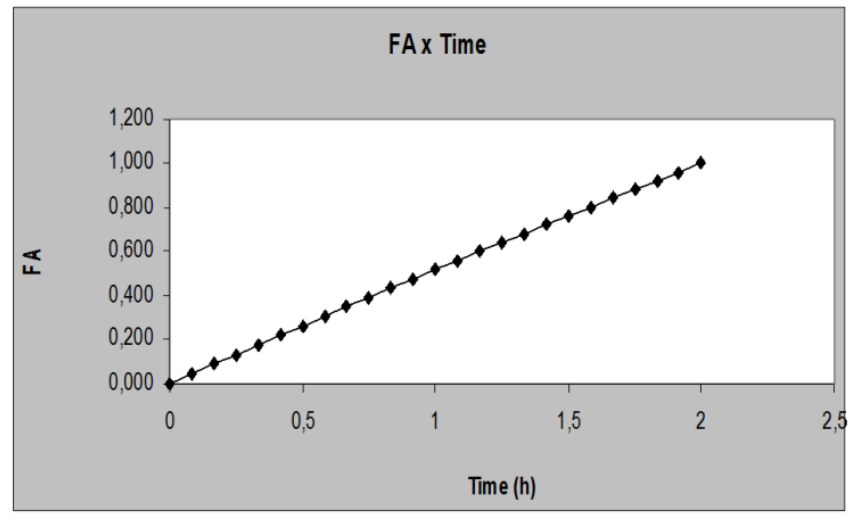

Figure 6. Plot of mean percentage of drug absorbed (FA) versus mean percentage of drug dissolved (FD) for Tolvon®.

\section{Conclusions}

The dissolution test developed and validated for mianserin hydrochloride was considered satisfactory. The method has the advantages of being very easy, fast and simple. The better conditions for dissolution was: $900 \mathrm{~mL}$ of medium containing $0.1 \mathrm{M} \mathrm{HCl}$, USP apparatus 2 (paddle) at $50 \mathrm{rpm}$ and $37 \pm$ $0.5{ }^{\circ} \mathrm{C}$. The UV method showed specificity, linearity, precision and accuracy. The in vitro dissolution test can be used to evaluate the drug release profile, but it was not possible to establish a correlation with in vivo data.

\section{Acknowledgments}

The authors are grateful to Coordenação de Aperfeiçoamento de Pessoal de Nível Superior (CAPES) for financial support.

\section{Conflict of interest}

None to declare.

\section{References}

1. Pawlowska J, Czarnocki Z, Wojtasiewicz K, Maurin J. Stereoselective synthesis of (R)-(-)-mianserin. Tetrahedron Asymm. 2003; 14(21): 3335-3342.

2. Xu P, Li H, Chen B, Ma N, Yan M, Zhu Y. Determination of mianserin in human plasma by high performance liquid chromatography-electrospray ionization mass spectrometry (HPLC-ESI/MS): Application to a bioequivalence study in Chinese volunteers. J. Pharm. Biomed. Anal. 2008; 47(4-5): 994-999.

3. Food and Drug Administration (FDA), Guidance for Industry: Dissolution Testing of Immediate Release Solid Oral Dosage Forms, Rockville, 1997.

4. US Pharmacopeial Forum, Pharmacopeial Previews, 2004, 30: 351-363.

5. Chauhan B, Rani S, Gutikkar S, Zope A, Jadon N, Padh H. Analytical method development and validation of mianserin 
hydrochloride and its metabolite in human plasma by LC-MS. J. Chromatogr. B. 2005; 823 (2): 69-74.

6. Hefnawy M, Aboul-Enein H. Fast high-performance liquid chromatographic analysis of mianserin and its metabolites in human plasma using monolithic silica column and solid phase extraction. Anal. Chim. Acta. 2004; 504(2): 291-297.

7. Khan IU, Aman T, Kazi AA, Khan ZA. Spectrophotometric determination of mianserin in pure and pharmaceutical preparations. J. Chem. Society of Pakistan. 2002; 24: 114. Abstract.

8. The United States Pharmacopoeia 42th ed., United States Pharmacopoeial Convention, Rockville, 2019.

9. Marques MRC, Brown W. Desenvolvimento e validação de métodos de dissolução para formas farmacêuticas sólidas orais. Rev. Anal. 2002; 01: 48.

10. Sfair LL, Graeff JS, Paim CS, Passos C, Steppe M, Schapoval, EES. Photodegradation kinetics, cytotoxicity assay and determination by stability-indicating HPLC method of mianserin hydrochloride. Pharm. 2012; 67(6):490494.

11. Bakshi M, Saranjit S. Development of validated stabilityindicating assay methods - critical reviews. J. Pharm. Biomed. Anal. 2002; 28(6): 1011-1040.

12. Skoug JW, Halstead DL, Theis DL, Freeman J, Fagam D, Rhors BR. Roteiro para desenvolvimento e validação do teste de dissolução em formas farmacêuticas sólidas para uso oral. Pharm. Tech. 1996; 5: 58.

13. Menegola J, Steppe M, Schapoval EES. Dissolution test for citalopram in tablets and comparision of in vitro dissolution profiles. Eur J Pharm Biopharm. 2007; 67:524 530 .

14. Marcolongo R. Dissertação de mestrado: Dissolução de medicamentos: fundamentos, aplicações, aspectos regulatórios e perspectivas na área farmacêutica. Universidade de São Paulo, São Paulo, (2003). 